\title{
Imej Tebu dalam Peribahasa Tamil: Analisis Semantik Inkuisitif (Sugar Cane images in Tamil Proverbs: A Semantic Inquisitive analysis)
}

\author{
TANGAPRABHU MURTHY* \& MARY FATIMAH SUBET
}

Fakulti Bahasa dan Komunikasi, Universiti Malaysia Sarawak, 94300 Kota Samarahan, Sarawak, Malaysia

*Corresponding author: tangaprabu@gmail.com

\begin{abstract}
ABSTRAK
Peribahasa dicipta hasil daripada pengamatan masyarakat terhadap keistimewaan alam semula jadi. Peribahasa juga mempunyai makna tersurat dan tersirat. Penggunaannya dapat menggambarkan kehalusan masyrakat berbahasa. Kajian ini dilaksanakan untuk mengesan kewujudan falsafah dan akal budi masyarakat India dalam penciptaan peribahasa serta mengesan makna sebenar yang ingin dikemukakan dalam peribahasa masyarakat India. Kerangka teori yang digunakan untuk mencapai objektif kajian ini ialah teori semantik inkuisitif oleh Nor Hashimah Jalaluddin (2014). Kajian ini ialah kajian kualitatif. Empat orang informan telah ditemu bual dan 25 data telah diperoleh. Dalam artikel ini, tiga data sahaja yang menggunakan imej tumbuhan tebu akan dibincangkan. Kajian mendapati penciptaan peribahasa masyarakat India amat berkait rapat dengan pengamatan mereka terhadap alam sekitar. Didapati juga, wujud maklumat falsafah dan akal budi masyarakat India dalam penciptaan peribahasa mereka. Makna sebenar yang dihajati juga dapat dirungkai setelah melalui tiga peringkat analisis dalam kaedah semantik inkuisitif. Akhir sekali, kajian sebegini lebih tinggi kesahannya kerana analisis makna menggunakan teori yang berwibawa. Kajian sebegini dapat menghuraikan makna implisit setiap peribahasa yang dicipta sehinggalah ke akal budi penuturnya.
\end{abstract}

Kata kunci: Peribahasa Tamil, semantik, semantik inkuisitif; falsafah dan akal budi penutur

\begin{abstract}
Proverbs are created when people started to observe and understand the nature around them. Proverbs consist of literal meanings and implicated meanings. The way these proverbs have been said, portrays the beauty and smoothness of the language to which the proverbs belong. This research is mainly conducted to distinguish Indian community's intellectual and philosophical abilities in conveying direct and indirect meanings. The theoretical framework used in this research is inquisitive semantics by Nor Hashimah Jalaluddin (2014). This is a qualitative research. The researcher attained 25 datas by interviewing four (4) Indian informants. However, this research acquired only three 3 data in which the image of sugarcane has been used. Finding shows that the Indian community's proverbs are established from their observation towards nature and the Indian community has their own philosophical understanding and also intellectual standards in the creation of proverbs. Actual meanings behind the data used in this research have been successfully decoded using the theory of inquisitive semantics. In a nutshell, this study is highly justifiable as the theory used in this research is a renowned and authoritative theory.
\end{abstract}

Keywords: Tamil proverbs, semantics, inquisitive semantics, philosophy and mind

Copyright: This is an open access article distributed under the terms of the CC-BY-NC-SA (Creative Commons AttributionNonCommercial-ShareAlike 4.0 International License) which permits unrestricted use, distribution, and reproduction in any medium, for non-commercial purposes, provided the original work of the author(s) is properly cited.

\section{PENGENALAN}

Menurut Za'ba (1965:165), “peribahasa ialah segala susunan cakap yang pendek yang telah melekat di mulut orang ramai sejak beberapa lama oleh sebab sedap dan bijak perkataannya, luas dan benar tujuannya dan dipakai akan dia jadi sebutan-sebutan oleh orang sebagai bandingan, teladan, dan pengajaran". Selain itu, penggunaannya mempunyai matlamat yang tersendiri, iaitu agar orang yang mendengar atau membacanya tidak mudah rasa tersinggung dalam sesebuah komunikasi. Peribahasa dikenali sebagai 'pazhamozhi' dalam bahasa Tamil. Menurut Parameswaran (2016), perkataan 'pazhamozhi' itu dapat dipisahkan kepada dua iaitu 'pazha' yang bermaksud keindahan bahasa yang diguna pakai sejak zaman dahulu dan perkataan 'mozhi' pula bermaksud bahasa. Beliau juga menyatakan bahasa orang dahulu lebih gemar menggunakan peribahasa atau 'pazhamozhi' itu untuk menyampaikan sesuatu hasrat tanpa menyinggung perasaan seseorang individu atau sekumpulan masyarakat dahulu mementingkan kesopanan dan keakraban yang juga menjadi budaya masyarakat India sehingga kini (Murthy dan Subet, 2018). Beliau juga menyatakan bahawa peribahasa Tamil muncul di 
negara kita melalui orang-orang Tamil yang datang ke Tanah Melayu sebagai pekerja dan kuli. Masyarakat yang datang ke negara kita membawa bersama tradisi, budaya, amalan, bahasa serta kepercayaan mereka. Jika dilihat dengan teliti penggunaan peribahasa merupakan amalan masyarakat India ketika dahulu dan mempunyai makna tersurat. Makna tersirat di sebalik peribahasa ini pula menceritakan bahawa kita sebagai manusia yang biasa akan menghadapi kesenangan serta kesusahan dalam hidup kita. Makna yang dikemukakan secara tersirat mempunyai kaitan dengan budaya, konteks penggunaan, pengalaman serta persekitaran, emosi, pendidikan dan pandangan tentang dunia (Subet \& Daud, 2018).

Peribahasa merupakan salah satu instrumen untuk melihat akal budi sesuatu masyarakat (Parameswaran, 2016). Limpahan peribahasa Tamil yang sedia ada pada masa kini merupakan bukti bahawa masyarakat India dahulu menggunakan bahasa yang halus dan implisit dalam pertuturan seharian mereka agar tidak menyakiti perasaan seseorang. Hal ini sejajar dengan masyarakat Melayu yang juga mengutamakan adab sehingga mencipta peribahasa agar tidak menyinggung perasaan seseorang itu. Walau bagaimanapun kajian ini hanya tertumpu kepada peribahasa Tamil sahaja dan penghuraian setiap makna peribahasa Tamil dilakukan dengan mengaplikasikan pendekatan semantik inkuisitif yang telah diperkenalkan oleh Nor Hashimah Jalaluddin pada tahun 2014. Pendekatan ini rancak digunakan dalam kebanyakan kajian antaranya Jalaluddin (2014a, 2014b, 2015), Kasdan dan Jalaluddin (2015), Wan Mansor dan Jalaluddin (2015, 2016), Wan Ismail (2016), Murthy (2017), Daud (2017, 2018a, 2018b), Daud dan Subet (2018) serta Murthy dan Subet (2018). Kajian ini bertujuan untuk mengenal pasti makna implisit di sebalik peribahasa Tamil yang menggunakan imej tebu serta pengaruh budaya yang menyebabkan lahirnya peribahasa yang melibatkan imej tebu di samping mengenali makna harfiah peribahasa Tamil yang menggunakan imej tebu. Manakala objektif kajian ini pula adalah untuk mengenal pasti peribahasa Tamil yang mengandungi imej tebu dan menganalisis makna implisit di sebalik penggunaan peribahasa Tamil berunsurkan imej tebu dengan mengaplikasikan pendekatan semantik inkuisitif serta menghuraikan pengaruh budaya, falsafah dan akal budi dalam peribahasa Tamil yang mengandungi imej tebu.

\section{METODOLOGI, KERANGKA TEORI DAN SUMBER DATA}

Penyelidik menggunakan kaedah yang bersifat kualitatif. Penyelidik menggunakan kaedah premier iaitu melalui temu bual mendalam. Penyelidik menemu bual seramai empat orang yang beragama Hindu dan mempunyai pendidikan bahasa Tamil. Dua orang merupakan informan lelaki dan dua orang lagi merupakan informan perempuan. Pendidikan bahasa Tamil di sini bermaksud seseorang yang mampu menulis, membaca dan dapat bertutur bahasa Tamil dengan fasih. Salah seorang informan merupakan orang tua yang berumur dalam lingkungan 80 tahun dan tiga orang lagi merupakan informan yang berpendidikan tinggi. Informan yang berumur 80 tahun itu merupakan informan yang tidak menerima pendidikan formal manakala tiga informan lagi merupakan guru di sebuah sekolah Tamil. Penyelidik membuat keputusan untuk memilih informan yang berbeza dari segi usia dan tahap pendidikan ini kerana untuk membezakan nilai kefahaman mereka terhadap peribahasa Tamil yang menggunakan imej tumbuhan serta mendapat data yang sahih. Seramai tiga orang informan itu dipilih mengikut norma manakala seorang lagi dipilih secara rawak mengikut taraf pendidikan dan pengetahuan dalam bahasa Tamil.

Pematuhan pemilihan informan juga adalah berdasarkan ciri NORF (Non Mobile, Old, Remote dan Female) dan NORM non-mobile (tinggal tetap), Older (tua), Rural (luar bandar), dan Male (lelaki) kerana pematuhan ini akan dapat memudahkan penyelidik melakukan temu bual. Persampelan yang menggunakan pemilihan secara NORF ini menurut Ong, Suri \& Aman (2016), lebih sesuai di Malaysia berbanding NORM. Walaupun begitu, pengkaji berpendapat kedua-dua informan lelaki dan informan perempuan akan dapat memberi maklumat untuk menghasilkan dapatan kajian yang bervariasi. Hal ini disebabkan oleh wujudnya keseimbangan data antara yang diambil sama ada lelaki mahupun perempuan. Menurut Omar (1993) juga, panduan pengutipan data daripada lelaki dan perempuan elok dipatuhi kerana mungkin dalam sesuatu masyarakat itu terdapat perbezaan antara bahasa lelaki dan perempuan dalam beberapa aspek tertentu. Selain itu, penyelidik menggunakan dua buah buku peribahasa dan mengambil beberapa contoh peribahasa yang serupa dengan data yang diperoleh untuk melihat maksud yang terkandung dalam buku tersebut serta dijadikan sebagai rujukan sahaja. Penyelidik mendapatkan segala data hasil daripada temu bual serta dua buah buku peribahasa Tamil iaitu Pazhamozhigal Naanuru (2013) dan Thamizh Naatu Pazhamozhigal 2000 (2013) digunakan sebagai rujukan. Segala data yang dirakam disimpan dengan rapi bagi menjaga kesahihan data tersebut.

\section{ANALISIS DAN PERBINCANGAN}

Sebanyak 25 peribahasa dikumpul melalui kaedah temu bual. Daripada jumlah ini, tiga (3) data akan dibincangkan dalam artikel ini. Peribahasa Tamil, transkripsi rumi dan maksud peribahasa tersebut adalah seperti dalam Jadual 1. 
Jadual 1. Senarai 3 peribahasaTamil yang mengandungi imej tebu (karumbu).

\begin{tabular}{|c|c|c|}
\hline Peribahasa Tamil & Transkripsi Rumi & Maksud \\
\hline $\begin{array}{l}\text { கரும்பிலும்தேள்இருக்கும், } \\
\text { கல்லிலும்பால்இருக்கும். }\end{array}$ & $\begin{array}{lr}\text { Karumbilum } & \text { theal } \\
\text { irukum, kallilum } & \text { paal } \\
\text { irukkum. } & \end{array}$ & $\begin{array}{l}\text { Walaupun seseorang itu jahat sifatnya, } \\
\text { orang tersebut masih akan memiliki } \\
\text { sifat-sifat yang baik. }\end{array}$ \\
\hline $\begin{array}{l}\text { கரும்புஇருக்க, } \\
\text { இரும்பைகடித்ததுபோல. }\end{array}$ & $\begin{array}{l}\text { Karumbu irukka irumbai } \\
\text { kadithathu pola. }\end{array}$ & $\begin{array}{l}\text { Melakukan perbuatan negatif } \\
\text { walaupun terdapat pelbagai cara yang } \\
\text { positif untuk melakukan sesuata kerja } \\
\text { tersebut. }\end{array}$ \\
\hline $\begin{array}{l}\text { கரும்புகட்டோடுஇருந்தால், } \\
\text { எரும்புதானாகவேவரும். }\end{array}$ & $\begin{array}{lr}\frac{\text { Karumbu }}{\text { irunthaal, }} & \text { kattodu } \\
\text { thanagavey varrum. }\end{array}$ & $\begin{array}{l}\text { Wanita yang kaya dari segi adat, } \\
\text { budaya serta mempunyai perwatakan } \\
\text { yang baik, tidak perlu mencari jodoh } \\
\text { malah jodoh tersebut akan datang pada } \\
\text { waktu yang sesuai mengikut rezeki } \\
\text { masing-masing. }\end{array}$ \\
\hline
\end{tabular}

Jadual 2. Analisis Peribahasa - Karumbilum theal irukum, kallilum paal irukkum.

\begin{tabular}{|c|c|c|c|}
\hline Peribahasa Tamil & Makna mudah & $\begin{array}{l}\text { Imej } \\
\text { tumbuhan }\end{array}$ & $\begin{array}{l}\text { Terjemahan } \\
\text { BM }\end{array}$ \\
\hline $\begin{array}{l}\text { Data } 1 \\
\text { கரும்பிலும்தேள்இருக்கும், } \\
\text { கல்லிலும்பால்இருக்கும். }\end{array}$ & $\begin{array}{l}\text { Walaupun seseorang itu jahat } \\
\text { sifatnya, orang tersebut masih } \\
\text { akan memiliki sifat-sifat yang } \\
\text { baik. }\end{array}$ & $\begin{array}{l}\text { Karumbu } \\
\text { Kalli }\end{array}$ & $\begin{array}{l}\text { Tebu } \\
\text { Kaktus }\end{array}$ \\
\hline $\begin{array}{l}\text { Transkripsi Rumi: Karumbilum theal } \\
\text { irukum, kallilum paal irukkum. }\end{array}$ & & & \\
\hline
\end{tabular}

Dalam peribahasa 'karumbilum theal ireku, kallilum paal irekum' peringkat analisis semantik skrip mengemukakan makna harfiah perihal di kawasan tanaman tebu (karumbu), kita dapat melihat kala jengking (theal), manakala dalam tumbuhan kaktus (kalli) kita dapat melihat susu (paal) di dalamnya. Rujuk Jadual 2.

Keupayaan kognitif mewujudkan persoalan kenapa di kawasan tanaman tebu, ada kaktus pula? Analisis makna peringkat semantik resonans perlu dilakukan. Ada sesuatu yang terungkap dalam pemikiran masyarakat yang mencipta peribahasa ini. Menurut informan, peribahasa ini menunjukkan bahawa walaupun seseorang itu jahat orangnya, namun nilai- nilai positif itu masih dapat dilihat padanya manakala orang yang baik tidak semestinya baik secara keseluruhannya. Orang tersebut juga akan mempunyai sifat-sifat negatif yang tidak diketahui orang. Inilah makna yang dikupas di peringkat resonans.

Memasukkan unsur kognitif untuk menelusuri makna peribahasa tersebut belum lagi memadai. Ada falsafah dan akal budi lagi yang perlu dicungkil. Mesti ada alasan kenapa masyarakat India menggunakan tebu (karumbu) serta mengapa mereka membandingkannya dengan tanaman kaktus (kalli)? Hal ini bersangkut paut dengan budaya, persekitaran, orang-orang di sekeliling mereka serta cara pergaulan mereka.

Perkaitan semua ini dapat dirungkai dengan menggunakan analisis semantik inkuisitif. Pertama, tebu (karumbu) merupakan sejenis tumbuhan yang manis sifatnya. Masyarakat India akan menggunakan tebu (karumbu) untuk mengaitkannya dengan hal-hal yang positif. Jika dilihat dengan lebih mendalam, walaupun tebu (karumbu) itu manis, bolehkah dikatakan di kawasan tanaman tebu itu tiada kala jengking (theal). Jawapannya sudah semestinya tidak. Kala jengking (theal) ini disifatkan sebagai suatu yang negatif dan boleh membawa maut jika terkena sengatan. Oleh hal yang demikian mereka menggunakan tebu (karumbu) untuk menjelaskan hal-hal yang positif di samping menggunakan kala jengking (theal) untuk menjelaskan sifat negatif itu. Hal ini amat berkait rapat dengan akal budi masyarakat itu sendiri. 
Seterusnya kenapa kaktus? Kenapa bukan durian, sebab durian pun berduri? Oleh itu, ada nilai falsafah di sebalik penggunaan imej kaktus ini. Penggunaan kaktus (kalli) dalam peribahasa tersebut juga mempunyai makna di sebalikya. Jika dilihat dari perspektif umum, pokok kaktus (kalli) merupakan sejenis tumbuhan yang berbatang hijau, berisi dan berduri. Duri yang terdapat pada kaktus itu dikatakan membawa nilai yang negatif mengikut masyarakat India kerana duri tersebut mampu mencederakan seseorang. Oleh hal yang demikian, mereka ingin menjelaskan bahawa walaupun pokok kaktus (kalli) diselaputi duri yang tajam, tanaman tersebut masih boleh mengeluarkan sejenis susu yang mungkin berguna kepada seseorang. Pokok kaktus (kalli) akan mengeluarkan sejenis susu apabila dipotong. Melalui kedua-dua imej tumbuhan ini, mereka ingin memberi nasihat kepada golongan muda supaya bijak memilih kawan kerana dalam suatu perbuatan jahat, kita masih boleh melihat sesuatu yang baik dan dalam suatu perbuatan yang baik terdapat nilai negatif di sebaliknya. Mereka memilih dua imej tumbuhan ini disebabkan sifat-sifat yang dimiliki oleh tumbuhan tersebut yang ingin mereka kaitkan dengan hidup manusia di alam nyata. Oleh itu dengan analisis semantik inkuisitif, makna sebenar peribahasa tersebut dapat dirungkai. Masyarakat India membandingkan dua perkara yang berbeza sifatnya iaitu satu benda yang manis rasanya dan satu lagi yang bahaya sifatnya iaitu kaktus (kalli) melalui ciptaan peribahasa Karumbilum theal irukum, kallilum paal irukkum.

Jadual 3. Analisis Peribahasa Karumbu irukka irumbai kadithathu pola.

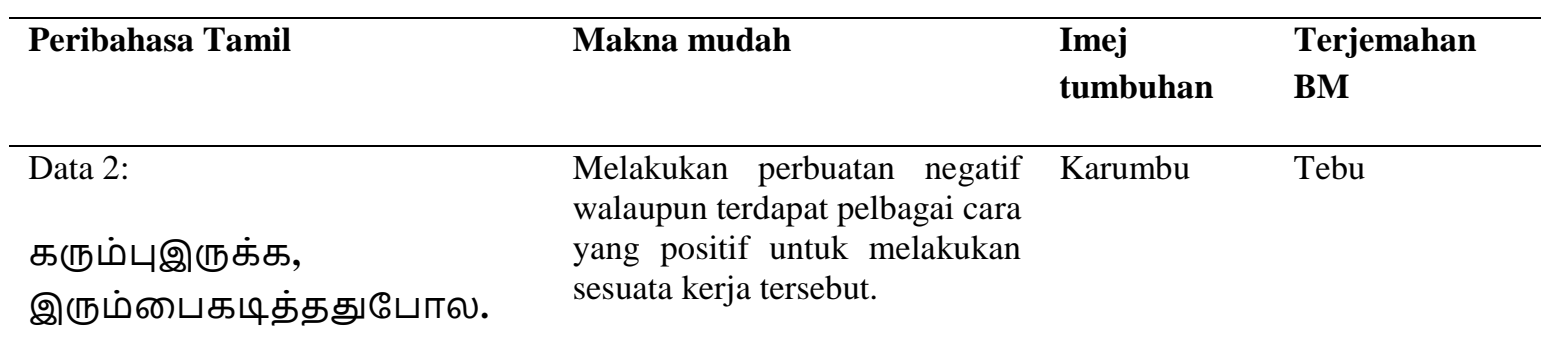

Transkripsi Rumi: Karumbu irukka

irumbai kadithathu pola.

Merujuk kepada Jadual 3, 'Karumbu irukka irumbai kadithathu pola' bermaksud menggigit besi yang tidak boleh memberi apa-apa rasa walaupun mempunyai tebu (karumbu) yang manis rasanya. Ini baru mencapai makna tahap skrip. Analisis semantik resonans merungkai ada pemikiran tersirat di sebalik peribahasa ini. Peribahasa ini menceritakan perbuatan seseorang yang melakukan kejahatan dan keburukan walaupun individu tersebut boleh melakukan kebaikan kepada diri, masyarakat serta negara. Peribahasa ini menimbulkan satu persoalan kepada pembaca. Kenapa hal ini yang difikirkan? Melalui peribahasa ini, masyarakat India ingin bertanya apa gunanya menggigit besi (irumbu) yang panjang seakan-akan seperti tebu (karumbu) namun tidak memiliki rasa dan tidak dapat dimakan. Lebih baik menggigit tebu (karumbu) yang manis rasanya serta dapat mengenyangkan perut. Ada falsafah dan akal budi dalam penciptaan peribahasa ini. Analisis dengan mengaplikasikan pendekatan semantik inkuisitif akan menemukan jawapannya.

Menurut (Maniam, 2016), tebu (karumbu) ini dikaitkan dengan semua hal yang positif oleh masyarakat India pada masa dahulu. Jika melihat sifat luaran tumbuhan tersebut, tebu (karumbu) itu panjang bentuknya, mempunyai daun selari, ruas dan keras sifatnya. Apabila melihat dari segi dalamnya, tebu (karumbu) itu mempunyai isi yang keras tetapi manis rasanya. Tebu (kerumbu) ini biasanya digunakan oleh masyarakat India dalam upacara 'ponggal' iaitu satu upacara yang dilakukan setelah tamatnya pesta menuai padi. Upacara ini dilakukan dengan menggunakan tebu (karumbu) sebagai tanda penghormatan serta tanda terima kasih kepada tanah yang memberi hasil. Hal ini kerana, tebu (karumbu) itu memang manis rasanya dan pasti disukai oleh semua lapisan masyarakat tidak kira yang muda mahupun yang tua. Oleh hal yang demikian, mereka menggunakan imej tumbuhan tebu (karumbu) dalam peribahasa untuk menunjukkan nilai-nilai positif. Tebu (karumbu) tersebut pula dibandingkan dengan besi(irumbu).

Besi disifatkan keras dan panjang dan mudah berkarat. Sifat ini dikaitkan dengan perangai negatif seseorang individu serta dibandingkan pula dengan tebu(karumbu) yang positif sifatnya kerana kemanisan yang dimiliki itu. Oleh itu, jelaslah bahawa masyarakat India menggunakan sifat imej tumbuhan di sekeliling mereka untuk dibandingkan dengan manusia dalam bentuk peribahasa di samping mendidik anak-anak muda tentang kepentingan tumbuhan kepada kita. Melalui analisis data ini, sudah jelas lagi terbukti bahawa akal budi masyarakat India terjelma dalam peribahasa ini. 
Jadual 4: Analisis Peribahasa - Karumbu kattodu irunthaal, erumbu thanagavey varrum.

\begin{tabular}{llll}
\hline Peribahasa Tamil & Makna mudah & $\begin{array}{l}\text { Imej } \\
\text { tumbuhan }\end{array}$ & $\begin{array}{l}\text { Terjemahan } \\
\text { BM }\end{array}$ \\
\hline Data 3: & $\begin{array}{l}\text { Wanita yang kaya dari segi adat, Karumbu } \\
\text { budaya serta mempunyai perwatakan }\end{array}$ & Tebu \\
கரும்புகட்டோடுஇருந்தால், & $\begin{array}{l}\text { yang baik, tidak perlu mencari jodoh } \\
\text { malah jodoh tersebut akan datang pada } \\
\text { எரும்புதானாகவேவரும். }\end{array}$ & $\begin{array}{l}\text { waktu yang sesuai mengikut rezeki } \\
\text { masing-masing. }\end{array}$ \\
$\begin{array}{l}\text { Transkripsi Rumi: Karumbu kattodu } \\
\text { irunthaal, erumbu thanagavey varrum. }\end{array}$ & & \\
\hline
\end{tabular}

Peringkat semantik skrip hanya memaparkan makna harfiah seperti yang dikemukakan di Jadual 4. Jika dilihat dari segi akal budi serta budaya masyarakat India, wanita dilihat sebagai satu ciptaan Tuhan yang luar biasa dan dihormati oleh setiap individu tanpa mengira usia baik yang muda mahupun yang tua. Jelas semantik resonans memaparkan pemikiran masyarakat India tentang wanita India secara sedemikian. Persoalannya, mengapakah wanita dikaitkan dengan tebu (karumbu)? Wanita itu manusia, tebu itu tumbuhan. Mesti ada sesuatu yang hendak disampaikan dalam peribahasa ini. Ada falsafah di sebalik penciptaannya dan penggunaan imej wanita yang dikaitkan dengan tebu.

Analisis semantik inkuisitif akan memberi makna sebenar di sebalik penggunaan wanita dan tebu. Makna perihal jodoh dalam makna skripnya belum cukup menjawab semua persoalan ini. Tafsiran resonans penggunaan tebu dan wanita juga belum dapat mengemukakan makna yang sebenar. Makna sebenar dapat dikesan apabila memasukkan analisis unsur falsafah dan akal budi di sebalik penciptaan peribahasa ini. Tumbuhan tebu ialah sejenis tumbuhan yang manis rasanya. Mengikut budaya orang India, setiap wanita itu dikatakan manis dan cantik. Manis dari segi perwatakan, dan cantik dari segi amalan budaya kaum tersebut. Seperti yang sudah dijelaskan dalam analisis berkaitan dengan tebu (karumbu) di atas, tebu (karumbu) selalunya dikaitkan dengan hal-hal yang positif. Oleh sebab itulah mereka menggunakan tebu (karumbu) dalam peribahasa tersebut. Peribahasa ini selalunya diguna pakai orang orang tua-tua untuk menasihati wanita atau remaja yang sudah matang (akil baligh). Melalui peribahasa tersebut mereka ingin menekankan bahawa setiap wanita yang matang dari segi pemikiran, bijak dalam membezakan baik buruk sesuatu perkara, kaya dari segi budaya dan dapat menjaga maruah diri serta keluarga akan mendapat jodoh tepat pada masanya dan mereka tidak perlu berlumba-lumba mencari jodoh mereka. Kajian ini juga mendapati bahawa mengikut budaya masyarakat India, wanita tidak dibenarkan memilih dan mencari jodoh mereka sendiri. Pihak lelaki yang perlu mencari wanita. Dengan hal yang demikian, memang tidak dapat disangkal bahawa orang tua-tua dahulu menekankan budaya mereka malah budaya dikatakan cerminan maruah mereka.

\section{KESIMPULAN}

Kajian ini membuktikan bahawa setiap peribahasa yang dicipta oleh masyarakat India mempunyai makna implisit di sebalik penciptaan tersebut. Terdapat keupayaan dan alasan kognitif di sebalik penciptaannya. Terdapat juga falsafah dan akal budi masyarakat di samping mempunyai ciri-ciri budaya yang mempengaruhi penciptaan peribahasa tersebut. Ciri-ciri budaya tersebut menyebabkan tercipta peribahasa untuk dijadikan suri teladan kepada masyarakat serta menjadi panduan dalam hidup. Peribahasa juga digunakan untuk menyampaikan mesej tanpa menyinggung perasaan orang yang mendengarnya. Melalui analisis yang telah dilakukan, objektif kajian ini telah dicapai sepenuhnya. Kajian ini juga membuktikan bahawa setiap peribahasa yang digunakan mempunyai makna implisit yang begitu mendalam sifatnya, selain membuktikan bahawa terdapat pelbagai sebab di sebalik penggunaan imej tumbuhan dalam setiap peribahasa yang dikaji. Akhir sekali, kajian ini diharap menjadi satu titik permulaan untuk mengenali falsafah dan akal budi masyarakat India di negara kita di samping menghidupkan semula penggunaan peribahasa dengan lebih meluas agar menjadi satu unsur kehalusan berbahasa ketika berkomunikasi, terutama sekali ketika menyampaikan nasihat dan teladan.

\section{RUJUKAN}

Daud, M. Z. (2018a). Domain rezeki dalam peribahasa Melayu berorientasikan Aves melalui perspektif semantik inkuisitif. MALTESAS Multi-Disciplinary Research Journal (MIRJO), 3(1), 19-28.

Daud, M. Z. (2018b). Gallus gallus domesticus dan Paradoxurus hermaphroditus dalam peribahasa Melayu: Analisis semantik inkuisitif. Sains Humanika, 10(2), 41-51. 
Daud, M. Z., \& Subet, M. F. (2018). Ayam (gallus gallus domesticus) dalam peribahasa Melayu: Analisis semantik inkuisitif. Jurnal Kemanusiaan, 16(1).

Gaunder, A. (2016). Routledge handbook of Japanese politics. London, UK: Routledge.

Jalaluddin, N. H. (2014a). Semantik dan akal budi Melayu. Selangor, Malaysia: Universiti Kebangsaan Malaysia.

Jalaluddin, N. H. (2014b). Pemugaran penyelidikan untuk pemerkasaan bahasa. Diperolehi daripada http://eseminar.dbp.gov.my/ceramahnj/kertas_kerja_norhashimah_jalaluddin.

Jalaluddin, N. H. (2015). Peribahasa 'Parasit' dan akal budi Melayu: Analisis semantik inkuisitif. Dlm Seminar Bahasa dan Sastera 2015 (pp. 281-293). Bangi, Malaysia: Pusat Pengajian Bahasa dan Linguistik, Universiti Kebangsaan Malaysia.

Kasdan, J., \& Jalaluddin, N. H. (2015). Unsur asam dan akal budi Melayu: Analisis semantik inkuisitif. Dlm Seminar Meja Bulat: Simpulan Bahasa dan Kognitif Penutur (pp. 1-20). Kuala Lumpur, Malaysia: Institut Alam dan Tamadun Melayu (ATMA), Universiti Kebangsaan Malaysia.

Kasdan, J., Jalaluddin, N. H., \& Wan Ismail, W. N. (2016). Ikan (Pisces) dalam peribahasa Melayu: Analisis semantik inkuisitif. International Journal of the Malay World and Civilisation (Iman), 4(1), 31-41.

Murthy, T. (2017). Imej tumbuhan dalam peribahasa Tamil: Suatu kajian semantik inkuisitif. (Tesis sarjana muda tidak diterbitkan). Universiti Malaysia Sarawak, Malaysia.

Murthy, T., \& Subet, M. F. (2018). Imej rumput dalam peribahasa Tamil: Suatu kajian semantik inkuisitif. Issues in Language Studies, 7(1).

Omar, A, H. (1993). Bahasa dan Alam Pemikiran Melayu. Kuala Lumpur. Dewan Bahasa dan Pustaka.

Parameswaran, G. (2016). Languages and the Tamil terms. Scribd Publisher.

Subet, M. F., \& Daud, M. Z. (2018). Makna denotatif dan konotatif dalam slanga pelacur. MALTESAS Multi-Disciplinary Research Journal (MIRJO), 3(1), 29-43.

Teck, O, S., Suri, N, S, A., \& Aman, R. (2016). Fonologi subdialek Pulau Pinang: satu kajian di Balik

Pulau. Gema: Online Journal of Language Studies, 13(1), 186-201.

Wan Mansor, N.A., \& Jalaluddin, N. H. (2016). Makna implisit bahasa kiasan Melayu: Mempertalikan komunikasi, kognisi dan semantik. Jurnal Komunikasi, 32(1), 189-206.

Za’ba (1965: 165). Ilmu Mengarang Melayu. (Edisi Kedua) Kuala Lumpur, Malaysia: Dewan Bahasa dan Pustaka.

Zakaria, S., \& Jalaluddin N. H. (2016). Konsep ruang dalam Cik Tunggal: Analisis semantik inkuisitif. Gema: Online Journal of Language Studies, 16(3), 187-204. 